\title{
Effects of climate indices on extreme rainfall in Queensland, Australia
}

\author{
Iqbal Hossain, H. M. Rasel, Monzur Alam Imteaz and Savalan Pourakbar \\ Department of Civil and Construction Engineering, Faculty of Science, Engineering and Technology, \\ Swinburne University of Technology, Melbourne, VIC 3122 \\ Email: ihossain@swin.edu.au
}

\begin{abstract}
Over the last 100 years, global surface temperature has increased approximately $0.75{ }^{\circ} \mathrm{C}$. One of the main concerns regarding global warming is the increased frequency and magnitude of extreme weather events, e.g. extreme rainfall which has already been recorded in many regions of the world. During the last decades, losses in economy and society have increased due to extreme climatic events. In certain parts of the world, society and its natural resources are damaged by extreme rainfall causing loss of lives and destruction of infrastructures. Increased frequency and magnitude of extreme rainfall led to the failure of existing drainage system and risk of increased flooding. Therefore, it is necessary to obtain information on extreme rainfall events for designing hydrologic and hydraulic infrastructures, e.g. stormwater management, urban drainage systems, water sensitive urban design (WSUD).

The increased frequency and magnitude of extreme rainfall events throughout the world led to increase concerns amongst hydrologists and water resources engineers in estimating the design rainfall derived from extreme rainfall frequency analysis. Since design rainfalls are important input in water resources engineering, errors in the selection of design rainfall event will cause devastating consequences for water infrastructure projects and flood mitigations works.

Although several studies on extreme rainfall events have been conducted and ongoing, regional dependency of the phenomena hinder in drawing generic conclusion. This paper investigates the effects of climate indices on extreme rainfall and its prediction. The extreme rainfall analysis will be performed using data from a rainfall station in Queensland. The analysis focusing on extreme events is easily understandable and manageable on impact studies and design rainfall estimation for water infrastructures. Comparing the modelled extreme rainfall with the observed outputs, it was found good predictive capability of the developed MLR models. The findings of the study also have significant importance for other regions of the world where there is considerable hydroclimatic variability.
\end{abstract}

Keywords: Climate indices, ENSO, IOD, multiple regression, rainfall forecasting 


\section{INTRODUCTION}

According to IPCC (2007), global surface temperature has been increased $0.75{ }^{\circ} \mathrm{C}$ over the last 100 years. The consequences of global warming are related to the extreme climatic events, e.g. excessive rainfall events producing floods and droughts. Hence, extreme rainfall events may have major impacts to society and natural resources through loss of lives and damaging of infrastructures (Acero et al., 2011). The increased frequency of extreme rainfall events has already been recorded in many regions of the world. Although the mean precipitation has been decreasing trends in some regions, extreme rainfall of that region has been recorded (Tryhon and DeGaetano, 2011).

Due global warming, the intensity and frequency of extreme rainfall events will be increased in near future except the regions that shows much decreased rainfall (IPCC, 2007). The extreme rainfall drives natural and human systems much more than the average climate (Permesan et al., 2000). Therefore, it is necessary to gather information on extreme rainfall for the wellbeing of the community, especially to populations living in the areas of increased flood risk. The information on extreme rainfall is necessary for designing flood protection and mitigation measures, urban drainage systems, water sensitive urban design (WSUD) techniques and so on. Hence, the study on the trends in the magnitude and frequency of extreme flow events are considerable concern to hydrologic and other branches of civil engineering (Pocernich, 2002).

Given the significance of increased magnitude and frequency of extreme rainfall events, and possible further increase of heavy rainfall events as a consequence of global warming, the urge for accurate and reliable extreme rainfall estimation has been raised. Therefore, watershed management authorities are looking methodologies for accurate and reliable prediction of extreme rainfall with much better understanding of climate and climatic influences. Different researchers (Yilmaz et al., 2014; Ahammed and Hewa, 2012; Jakob et al., 2011) tried to predict sub-daily extreme rainfall using stationary and non-stationary climatic conditions. However, almost all of the studies were performed to develop intensity-frequency-duration (IFD) curve.

For the prediction of water resources and hydrological variables, multiple regression models are commonly used. Many researchers have used multiple regression (MLR) models for rainfall forecasting (He et al., 2014) and flood forecasting (Latt et al., 2014). Ihara et al. (2007) used multiple regression models to investigate the relationship between ENSO and Indian Ocean indices with summer monsoon rainfall. Mekanik et al., (2013) examined the influence of lagged ENSO and IOD on Victorian rainfall using multiple regression models. However, the predictive capability of currently used models beyond 1 week and shorter than a season is still questionable (Hudson et al., 2011). According to Vitrat (2004), the usual forecast systems (the models) generally lost information from the atmospheric initial conditions that are basis for weather forecasts. In the first month of the forecasting period, the ocean state might not change much since the start of the prediction. On the other hand, no such study has been conducted to find out the relationship between the climate drivers and extreme rainfall in this region.

This paper investigates the potential effects of climate indices on extreme rainfall using the data collected from Queensland. Extreme rainfall forecasting has given consideration for problem related engineering design and risk management for stormwater drainage systems, buildings, bridges and culverts. The main objective of the paper is to forecast extreme rainfall in Queensland using MLR techniques.

In Australia, very limited effort has been given in the investigation of potential influence of climate indices on extreme rainfall events. However, monthly or seasonal rainfall forecasting with climate indices using MLR modelling techniques are commonly used in Australia (Mekanik et al., 2013). Therefore, this study will increase the understanding of climate indices on extreme rainfall forecasting as well as provide an indication to the policy makers and practitioners for the design of water resources infrastructures projects and flood mitigations strategies through developed improved methodology to forecast extreme rainfall.

\section{DATA AND ADOPTED METHODOLOGY}

Good quality data are required for the development, calibration and estimation of the any model (Marsden et al. 1973). According to Boorman (2003), without fully understanding data availability is clearly a weakness 
in any study that has no data collection program. In this study, historical rainfall data was collected from the Australian Bureau of Meteorology website (www.bom.gov.au/climate/data/). The rainfall station Augathella post office from Queensland was selected as the case study. The stations were selected based on the recorded length of data having fewer missing values. Observed monthly rainfall in millimetres was collected for the selected station from January 1890 to December 2013. Since the main objective of the study was the investigation of influence of climate indices on rainfall, the climate indices data was obtained from Climate Explorer website (http://climexp.knmi.nl). The obtained data (both rainfall and climate indices) from the respective organisations were divided into two sets for the calibration and validation respectively. Data from 1890 to 2008 were used for the calibration and data from 2009 to 2013 was used for the validation of the developed MLR models.

To achieve the objective of this study, MLR modelling technique was used. MLR is linear statistical modelling technique which is used to find out the best relationship between a variable and several other variables through least square method. The general equation for MLR model can be expressed as follows:

$Y=c_{0}+a_{1} X_{1}+a_{2} X_{2}+e$

Where, $\mathrm{Y}$ is the depended variable (rainfall in this case); $\mathrm{X}_{1}$ and $\mathrm{X}_{2}$ are the variables of MLR equation (ENSO and IOD in this case), $a_{1}$ and $a_{2}$ are the coefficients of the respective variables; $c_{0}$ is constant and e is error.

Model evaluation is a technique that determines whether the initiative is worthwhile in terms of delivering the expected output. To check some of the implications into prediction of any scientific model, the best way is evaluating the modelling outcomes. In this research, the performances of the developed MLR models were evaluated by implementing several error indices and statistical performance tests. The agreement or the disagreement of the observed daily maximum rainfall data with the developed MLR models were evaluated using widely used statistical methods, e.g. root mean square error (RMSE), Pearson correlation coefficients (R), Willmot index of agreement (d). To check the presence of multicolinearity amongst the modelled outputs, Tolerance $(\mathrm{T})$ statistical test was also performed.

\section{RESULTS AND DISCUSSION}

In this research individual correlation between Queensland extreme rainfall and monthly climate indices (DMI, Nino3.4, and SOI) were investigated. The statistical significant correlations of extreme rainfall with climate indices were further analysed using MLR for rainfall forecasting. The analysis showed that extreme rainfall has significant correlations with September, October and November DMI, Nino3.4 and SOI. Pearson correlations of the individual climate predictors with extreme rainfall of Western Australia are shown in Table 1 .

Table 1: Significant Pearson correlation (R) coefficient between extreme rainfall and climate indices

\begin{tabular}{|c|c|c|c|c|c|}
\hline \multirow{2}{*}{ Region } & \multirow{2}{*}{ Station } & \multirow{2}{*}{$\begin{array}{c}\text { Climate } \\
\text { indices }\end{array}$} & \multicolumn{3}{|c|}{ Lagged climate indices } \\
\cline { 3 - 6 } & & & Sep. & Oct. & Nov. \\
\hline \multirow{2}{*}{ QLD } & \multirow{2}{*}{$\begin{array}{l}\text { Augathella } \\
\text { Post Office }\end{array}$} & DMI & $-0.18^{*}$ & $-0.23 *$ & - \\
\cline { 3 - 6 } & & Nino3.4 & $-0.20^{*}$ & $-0.22^{*}$ & $-0.25^{* *}$ \\
\cline { 3 - 6 } & & SOI & $0.35^{* *}$ & $0.29 * *$ & $0.29 * *$ \\
\hline
\end{tabular}

* Correlation is significant at the 0.05 level; ** Correlation is significant at the 0.01 level

From Table 1, it is clear that extreme rainfall significantly relies on ENSO climate indices particularly SOI compared with DMI. Maximum correlation between extreme rainfall and individual indices was observed 0.35. Extreme rainfall was also significantly influenced by September, October and November Nino3.4; and maximum correlation was in November which is 0.25 . 
To assess the combined effect of the climate modes on extreme rainfall, the drivers with significant correlations months were further analysed using MLR modelling technique. MLR was performed to investigate the predictability of extreme rainfall using DMI-Nino3.4 and DMI-SOI combination to find out the potential combined predictors. The tests for Tolerances $(\mathrm{T})$ of the developed combined models were also investigated. Amongst the developed forecasting models of the MLR analysis, the models having lower errors were selected as the best models for extreme rainfall forecasting. The summary of the best MLR models for the station along with the values of regression coefficients are shown in Table 2.

Table 2: Variables and constants extracted from the best MLR models

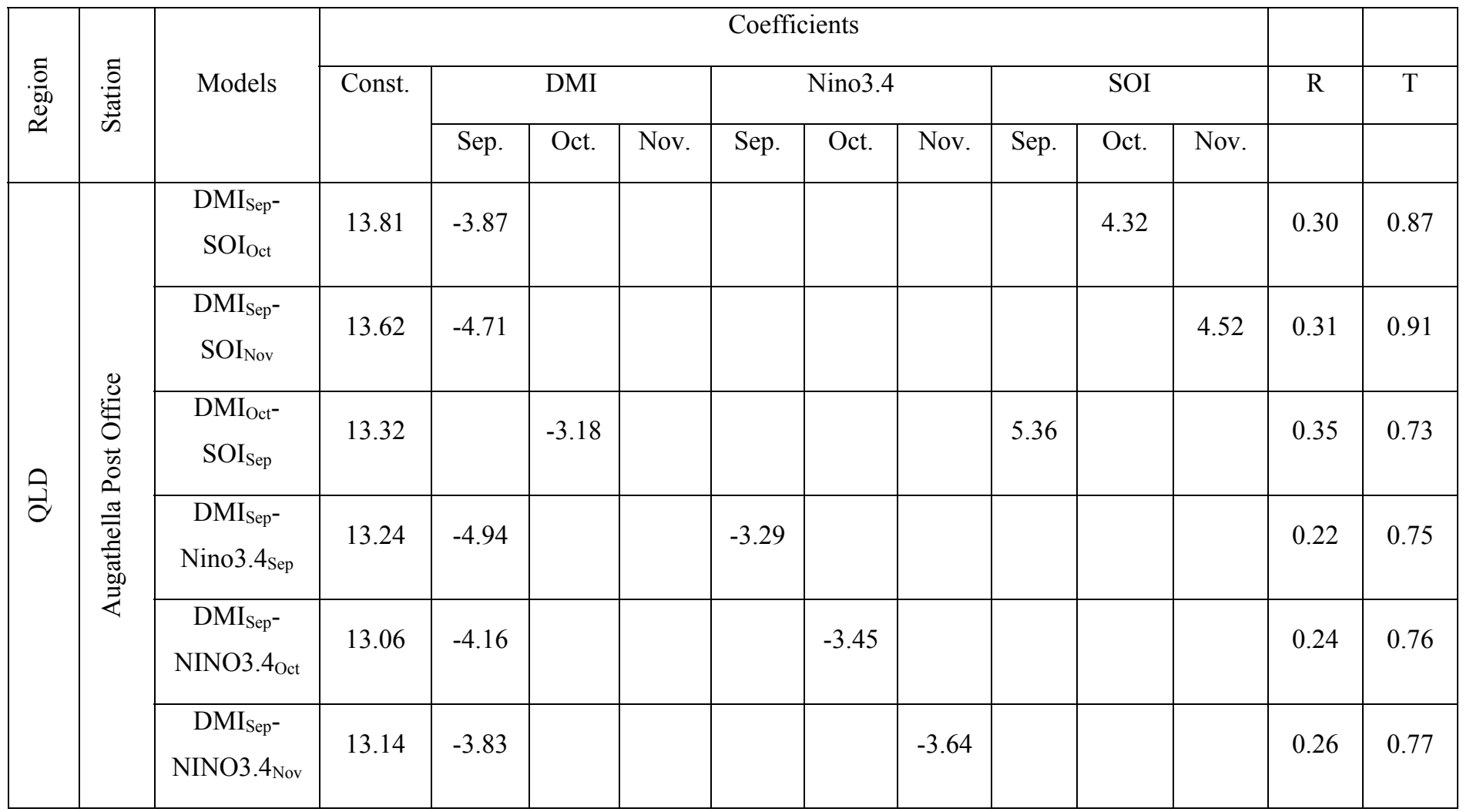

It is clear from Table 2 that $\mathrm{T}$ statistical tests were close to one confirming that the residuals of the predicted models have no autocorrelations and they are independent. Therefore, it assured the statistical goodness-of-fit of the models.

Table 3: Performance of the MLR developed models

\begin{tabular}{|c|c|c|c|c|c|}
\hline Region & Station & Models & $\mathrm{R}$ & RMSE & d \\
\hline \multirow{6}{*}{ QLD } & \multirow{6}{*}{$\begin{array}{l}\text { Augathella } \\
\text { Post Office }\end{array}$} & $\mathrm{DMI}_{\text {Sep- }}-\mathrm{SOI}_{\mathrm{Oct}}$ & 0.28 & 16.44 & 0.36 \\
\hline & & $\mathrm{DMI}_{\mathrm{Sep}}-\mathrm{SOI}_{\mathrm{Nov}}$ & 0.30 & 16.37 & 0.37 \\
\hline & & $\mathrm{DMI}_{\text {Oct }}-\mathrm{SOI}_{\mathrm{Sep}}$ & 0.34 & 16.16 & 0.44 \\
\hline & & $\mathrm{DMI}_{\text {Sep}}-\mathrm{Nino3.4}_{\mathrm{Sep}}$ & 0.20 & 16.79 & 0.27 \\
\hline & & DMI $_{\text {Sep }}-$ NINO3.4 Oct & 0.22 & 16.72 & 0.29 \\
\hline & & $\mathrm{DMI}_{\mathrm{Sep}}-\mathrm{NINO} 3.4_{\mathrm{Nov}}$ & 0.25 & 16.61 & 0.32 \\
\hline
\end{tabular}

Various performances of statistics, such as MLR correlations (R), RMSE and index of agreement (d) of the best MLR models for the station are shown in Table 3. It was observed that DMI-Nino3.4 based combined 
predictor models demonstrated statistically significant results with good forecasting capability of extreme rainfall in Queensland with $\mathrm{R}=0.34$.

MLR models in validation stage showed very compatible predictive capability of the selected stations with $\mathrm{R}$ close to 0.80 to forecasts the sample test set. The RMSE of the validation data set are much lower compared to the calibration stage shown in Table 4. This indicates good forecasting capability of May rainfall with the developed models with a high level of accuracy. All the calculated ' $d$ ' values in the validation set are more than 0.60 confirming that the combined climate predictors models are capable of forecasting Queensland's extreme rainfall.

Table 4: Performance of the MLR models for the test sets

\begin{tabular}{|c|c|c|c|c|c|}
\hline Region & Station & Models & $\mathrm{R}$ & RMSE & d \\
\hline \multirow{6}{*}{ QLD } & \multirow{6}{*}{$\begin{array}{l}\text { Augathella } \\
\text { Post Office }\end{array}$} & DMISep- SOIoct & 0.84 & 9.00 & 0.72 \\
\hline & & $\mathrm{DMI}_{\mathrm{Sep}}-\mathrm{SOI}_{\mathrm{Nov}}$ & 0.74 & 10.25 & 0.64 \\
\hline & & DMIoct- SOISep & 0.66 & 8.17 & 0.81 \\
\hline & & $\mathrm{DMI}_{\text {Sep }}-$ Nino3.4 & 0.87 & 10.35 & 0.57 \\
\hline & & $\begin{array}{c}\text { DMI }_{\text {Sep- }} \\
\text { NINO3.4 }{ }_{\text {Oct }}\end{array}$ & 0.83 & 10.29 & 0.58 \\
\hline & & $\mathrm{DMI}_{\mathrm{Sep}}-\mathrm{NINO} 3.4_{\mathrm{Nov}}$ & 0.75 & 9.98 & 0.62 \\
\hline
\end{tabular}

The best predicted models were selected considering the lower errors, higher $\mathrm{R}$ and $\mathrm{d}$ values. The best predicted model developed for the Augathella post office station is shown by the following equation:

Rainfall $=13.32-3.18 \mathrm{DMI}_{\mathrm{Oct}}-5.36 \mathrm{SOI}_{\text {Sep }}$

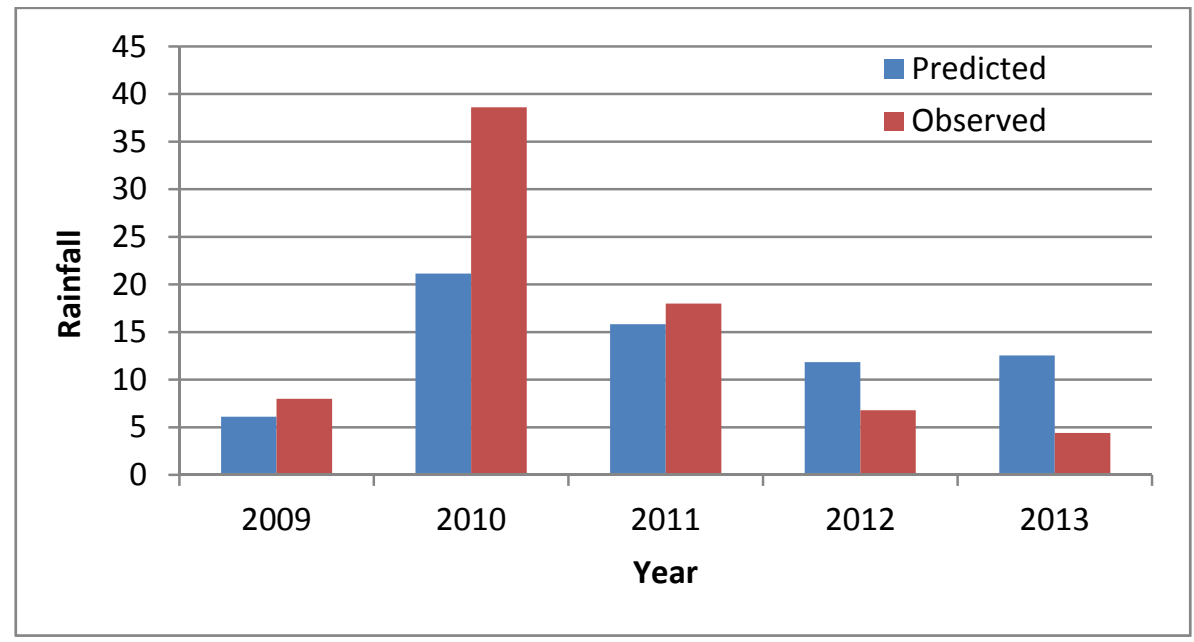

Figure 1. $\mathrm{DMI}_{\mathrm{Sep}}-\mathrm{SOI}_{\mathrm{Oct}}$ Validation modelling outputs

Figures 1 to 2 present the outputs from the best developed MLR models. From the Figures, it is clear that the developed MLR models were capable of producing the observed extreme rainfall with some variation. As we know that rainfall is the final result of complex global atmospheric global phenomena, prediction of extreme rainfall remains challenge. Instead of only two climate indices, influences of other factors were responsible for the variation of intense rainfall. 


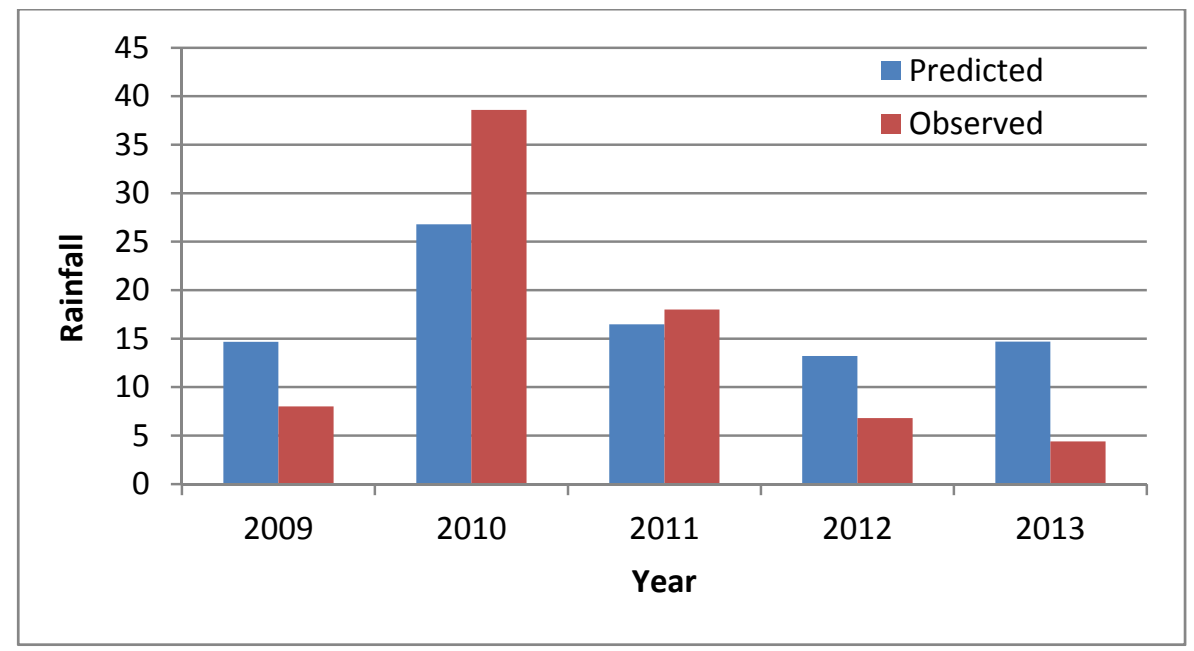

Figure 2. $\mathrm{DMI}_{\mathrm{Oct}}-\mathrm{SOI}_{\mathrm{Sep}}$ Validation modelling outputs

The prediction results, various statistical evaluation parameters as well as statistical significances demonstrated the capability of developed DMI-ENSO based combined MLR models in forecasting Queensland extreme rainfall with good accuracy. However, some parts of the duration the models are over estimating and some parts they are under estimating from the actual observation. These variations in the prediction are due to the other climatic drivers.

\section{CONCLUSIONS}

Attempt has been made for the prediction of Queensland extreme rainfall by considering single and combined climate indices DMI and ENSO as potential predictors. In this study, climate indices DMI and Nino3.4 were selected. The Pearson correlation coefficients of extreme rainfall with each individual climate indices were used to select combination of indices for further analysis with MLR technique. It was discovered that extreme rainfall exhibits significant correlations with three months climate indices (September, October and November). The outputs of the analysis showed that discrete impacts Nino3.4 (ENSO climate drivers) and DMI both have strong influence at Augathella Post Office in Queensland, Australia.

Furthermore, the developed MLR models were validated to investigate the predictive capability of extreme rainfall with separate data set. The statistical errors (RMSE and d) of the validation period for the developed MLR models were lower compared to the calibration period of the data set. Moreover, all the ' $d$ ' values in the validation stage are more than 0.5. This indicates that DMI-ENSO based models could be improved forecasting model for the prediction of Queensland extreme rainfall. Further investigation of MLR technique should be performed in this region to suggest a generalize model for forecasting monthly rainfall in this region.

\section{REFERENCES}

Acero, F.J., Garcia, A., and Gallego, M.C., 2011. Peaks over threshold study of trends in extreme rainfall over the Iberian Peninsula. Journal of Climate, 24, 1089-1105.

Ahammed F. and Hewa, G.A. (2012). Development of hydrological tools using extreme rainfall events for Dhaka, Bangladesh. Water International, 37(1): pp. 43-52.

Boorman, D.B. (2003). LOIS in-stream water quality modelling. Part 1. Catchments and methods. The Science of the Total Environment, 314-316, pp. 379-395.

He, X., Guan, H., Zhang, X. and Simmons, C. T. (2014). A wavelet-based multiple linear regression model for forecasting monthly rainfall. International Journal of Climatology, 34, 1898-1912. 
Hudson D, Alves O, Hendon HH, Wang G. 2011. The impact of atmospheric initialisation on seasonal prediction of tropical Pacific SST. Climate. Dynamics. 36: pp. 1155-1171.

Ihara, C., Kushnir, Y., Cane, M. A. and De La Pena, V. H. 2007. Indian summer monsoon rainfall and its link with ENSO and Indian Ocean climate indices. International Journal of Climatology, 27, 179-187.

IPCC, (2007). "Climate Change 2007: The Physical Science Basis, Contribution of Working Group I to the Fourth Assessment Report of the Intergovernmental Panel on Climate Change." edited by:Solomon, S., Qin, D., Manning, M., Chen, Z., Marquis, M., Averyt, K. B., Tignor, M., and Miller, H. L., Cambridge, United Kingdom and New York, USA, 996 pp., 2007.

Jakob, D., Karoly, D. J., and Seed, A. (2011): Non-stationarity in daily and sub-daily intense rainfall - Part 1: Sydney, Australia. Natural Hazards Earth System Sciences, 11: pp. 2263-2271.

Latt, Z. Z. and Wittenberg, H. (2014). Improving Flood Forecasting in a Developing Country: A Comparative Study of Stepwise Multiple Linear Regression and Artificial Neural Network. Water Resources Management, 28, 2109-2128.

Marsden, J.R., Pingry, D.E. and Whinston, A. (1973). Application of nonlinear programming to water quality control. Water, Air, and Soil Pollution, 2(2): pp. 155-169.

Mekanik, F., Imteaz, M.A., Gato-Trinidad, S. and Elmahdi, A. (2013). Multiple linear regression and artificial neural network for long-term rainfall forecasting using large scale climate modes. Journal of Hydrology, 503: pp. 11-21.

Parmesan, C. Root, T.L. and Willig, M.R. (2000). Impacts of Extreme Weather and Climate on Terrestrial Biota. Bulletin of the American Meteorological Society, 81(3): pp. 443-450.

Pocernich, M.J. (2002). Application of extreme value theory and threshold models to hydrological events. MSc. Thesis, University of Colorado at Denvar.

Tryhorn, L. and DeGaetano, A.: A comparison of techniques for downscaling extreme precipitation over the Northeastern United States, International Journal Climatology, 31, 1975-1989, 2011.

Vitart F. 2004. Monthly forecasting at ECMWF. Monthly Weather Review 132: pp. 2761-2779.

Yilmaz, A.G., Hossain, I. and Perera, B.J.C. (2014). Effect of climate change and variability on extreme rainfall intensity-frequency-duration relationships: a case study of Melbourne. Hydrology and Earth System Sciences, 18: pp. 4065-4076. 